\title{
Use of alcohol in the elderly: transcultural validation of the Michigan Alcoholism Screening Test - Geriatric Version (MAST-G)
}

\author{
USO DO ÁLCOOL EM IDOSOS: VALIDAÇÃO TRANSCULTURAL DO MICHIGAN \\ ALCOHOLISM SCREENING TEST - GERIATRIC VERSION (MAST-G
}

CONSUMO DE ÁLCOHOL EN ANCIANOS: VALIDACIÓN TRANSCULTURAL DEL MICHIGAN ALCOHOLISM SCREENING TEST - GERIATRIC VERSION (MAST-G)

\author{
Marcia Yumi Kano1, Manoel Antônio dos Santos², Sandra Cristina Pillon ${ }^{3}$
}

\begin{abstract}
Objective: To evaluate the internal consistency of the version of the Michigan Alcoholism Screening Test - Geriatric Version (MAST-G) instrument, translated and adapted for Brazil. Method: This was a descriptive, cross-sectional study. Data were collected through a demographic questionnaire, the ICD-10 and the MAST-G, following the steps of translation and cultural adaptation. One hundred eleven elderly in the city of São Carlos, SP, Brazil were interviewed. Results: The mean age of those interviewed was 70 years, with $45 \%$ men and $55 \%$ women, with the mean education of three years; $92 \%$ resided with family; $48 \%$ of the subjects consumed alcoholic beverages. The MAST-G presented a good level of reliability, with Cronbach's $\alpha=0.7873$, and good levels of sensitivity and specificity with a cutoff score of five positive responses. Conclusion: The Brazilian version of the MAST-G presented internal consistency values similar to the original English version, showing it to be adequate for use in the national context.
\end{abstract}

\section{RESUMO}

Objetivo: Avaliar a consistência interna da versão traduzida e adaptada para o Brasil do instrumento Michigan Alcoholism Screening Test - Geriatric Version (MAST-G). Método: Estudo descritivo de corte transversal. Os dados foram coletados por meio de um questionário com informações sociodemográficas, o CID-10 e o MAST-G, seguindo as etapas de tradução e adaptação transcultural. Foram entrevistados 111 idosos do município de São Carlos, SP, Brasil. Resultados: A média de idade dos entrevistados foi de 70 anos, sendo $45 \%$ homens e $55 \%$ mulheres, com escolaridade média de três anos; $92 \%$ residiam com a família; $48 \%$ dos sujeitos consumiam bebida alcoólica. $O$ MAST-G apresentou bom índice de confiabilidade, com Alfa de Cronbach $\alpha=0,7873$, e bons índices de especificidade e sensibilidade, com nota de corte de cinco respostas positivas. Conclusão: A versão brasileira do MAST-G apresentou valores de consistência interna semelhantes aos da versão original em inglês, mostrando-se adequada para uso no contexto nacional.

\section{DESCRIPTORS}

Aged

Alcohol-related disorders

Validation studies

\section{DESCRITORES}

Idoso

Transtornos relacionados ao uso de álcool Estudos de validação

\section{RESUMEN}

Objetivo: Evaluar la consistencia interna de la versión traducida y adaptada para Brasil del instrumento Michigan Alcoholism Screening Test-Geriatric Version (MAST-G) - Prueba de detección del alcoholismo de Michigan - Versión Geriátrica. Método: Estudio descriptivo de corte transversal. Los datos fueron recogidos mediante un cuestionario con informaciones sociodemográficas, CIE-10 y MAST-G, siguiendo las etapas de traducción y adaptación transcultural. Fueron entrevistados a 111 ancianos de la ciudad de São Carlos, SP, Brasil. Resultados: El promedio de edad de los entrevistados fue de 70 años, siendo el $45 \%$ varones y el $55 \%$ mujeres, con escolaridad media de tres años; el 92\% vivían con la familia; el $48 \%$ de los sujetos consumían bebidas alcohólicas. El MAST-G presentó buen índice de fiabilidad, con Alfa de Cronbach $\alpha=0,7873$ y buenos índices de especificidad y sensibilidad, con nota de corte de cinco respuestas positivas. Conclusión: La versión brasileña del MAST-G ha presentado valores de consistencia interna similares a los de la versión original en inglés, mostrándose adecuada para su empleo en el marco nacional.

\section{DESCRIPTORES}

Anciano

Trastornos relacionados com alcohol

Estudios de validación

${ }^{1}$ Master's in Sciences, School of Nursing of Ribeirão Preto, University of São Paulo, Ribeirão Preto, SP, Brazil. ${ }^{2}$ Associate Professor, Department of Psychology, School of Philosophy, Sciences and Letters of Ribeirão Preto, University of São Paulo, Ribeirão Preto, SP, Brazil. ${ }^{3}$ Professor, Department of Psychiatric Nursing and Human Sciences, School of Nursing of Ribeirão Preto, University of São Paulo, Ribeirão Preto, SP, Brazil. 


\section{INTRODUCTION}

It is estimated that, in 2025 , there will be 1.2 billion people in the world over 60 years of age and, in 2050, this number could reach two billion ${ }^{(1)}$. According to data obtained in the 2010 Census, the Brazilian population was $190,755,799$ inhabitants, of which 20,590,599 (10.8\%) were at least 60 years of age. If, on the one hand, the growing aging population has brought the benefits of increased longevity desired by all, on the other it has introduced a new profile of morbidity-mortality characterized by the increase and accumulation of chronic noncommunicable diseases ${ }^{(2)}$. The inversion of the demographic pyramid reflects increased life expectancy due, principally, to the advances in medical technology. However, the transitions in social roles can foster abusive and chronic alcohol consumption in the elderly population, leading to short and long term harm to health (dementia cases, cirrhosis, pancreatitis, aggravation of preexisting symptoms), as well as changes in behavior. It can be said that alcoholism is a chronic disease, progressive and potentially fatal, characterized by symptoms such as the lack of control over the use of alcohol and a constant preoccupation with the ingestion of alcoholic beverages, inducing its consumption despite adverse consequences. Symptoms may be accompanied by distortions in thinking, most notably denial about the addiction and the harmful effects of consumption on the health and well-being of the individual(3).

The peculiarities involved in the different age ranges need to be considered, as is the case of the elderly population in relationship to alcohol use. In Brazil, the prevalence of alcoholism among people 15 to 65 years is approximately $13 \%$, recognized as a determining factor in over $10 \%$ of all morbidity and mortality ${ }^{(4-5)}$. In the elderly population, data from the first national survey on the patterns of alcohol consumption ${ }^{(6)}$ showed that $7 \%$ of the elderly frequently consumed alcohol, $8 \%$ very frequently, $10 \%$ occasionally, $8 \%$ rarely, and $68 \%$ never drank or consumed alcohol, at the most, one time per year. A population study conducted in the metropolitan region of São Paulo with a sample of 169 elderly men identified a high rate of current abstinence $(61.6 \%)$ and, of the total, $38 \%$ were former drinkers ${ }^{(7)}$.

The prevalence of elderly alcoholics in the general population is estimated at $10 \%{ }^{(8)}$, in hospital emergency departments $14 \%$, in admissions to medical wards $18 \%$, in psychiatric units $23-40 \%$, and in specialized services $2-4 \%$. It is one of the most common problem among elderly men $^{(4,8-9)}$.

Several factors can contribute to the hinder the identification of this disease among the elderly, such as denial of alcohol consumption, abuse or dependence; the lack of protocols that favor physicians and other health professionals properly investigating the alcohol-related problems when addressing elderly patients; and even the fact that family members, caregivers and friends collaborate, unconsciously, with the elderly in denying the existence of alcohol misuse. Moreover, existing programs in clinical detoxification and rehabilitation are still scarce in the approach of specific topics related to the elderly population ${ }^{(3)}$.

Considering the difficulty of detection of the abuse of alcohol in the elderly population, it is necessary to endeavor to develop and validate screening instruments in this age range. In view of the need to produce new knowledge in the area of health care for elderly, a research issue that was the origin of the current study is the transcultural adaptation of a screening instrument for the detection of alcohol abuse and dependence, in its version for individuals over 65 years.

In 1971, the Michigan Alcoholism Screening Test (MAST) was published, developed and adapted for young adults ${ }^{(10)}$. During the following years, this instrument had adaptations and, in 1992, the Michigan Alcoholism Screening Test - Geriatric Version (MAST- G) ${ }^{(11)}$ was published, with the goal of detecting alcohol abuse and probable dependence in elderly individuals. Its development was important due to the specific method for elderly with problems related to the consumption of alcohol. The instrument contained 24 dichotomous questions, developed according to the DSM-III Revised (DSMIII-R) criteria.

There was a consensus that this tool identified alcohol use, abuse and probable dependence in the elderly. Thus, the MAST-G became an important ally of health professionals, when one intended to obtain a broader view of the biopsychosocial life of the elderly; since it could provide a better quality of care, as well as providing insight for counseling, treatment and rehabilitation ${ }^{(12-13)}$.

The MAST-G was developed in two phases, which were a pilot test followed by validation. Early in the development of the instrument, after several research studies, a total of 94 items were computed. In the pilot test the quality of writing and understanding of items was investigated. One hundred twenty-five people participated, aged greater than 55 years, from various locations and from different communities and clinics. In this evaluation, sociodemographic data were also recorded and the existence of health problems was verified. Even at this stage, the questionnaire was again submitted to 840 people, over the age of 55 years. After evaluating the results; the final version of the instrument resulted in 32 items $^{(14)}$.

In the validation phase, a sample of 280 people was used, with an age greater than 66 years. The subjects were classified into five groups: (1) those who fulfilled the criteria for alcohol dependence and were not in treatment; (2) those who were being treated for alcoholism; (3) those with a history of alcoholism who were in recovery; (4) social drinkers; (5) abstainers. With these groups, the objec-
Use of alcohol in the elderly: transcultural validation of the Michigan Alcoholism Screening Test - Geriatric Version (MAST-G) Kano MY, Santos MA, Pillon SC 
tive was to expect the most diverse sample possible and to ensure that it was representative of the drinking behavior of the elderly. As the gold standard for validation, the DSM-III-R was used. Thus, the MAST-G resulted in an instrument consisting of 24 items.

The MAST-G has been used in various countries, presenting, in the majority of cases, high specificity and sensitivity ${ }^{(15-17)}$. The psychometric properties of this instrument were shown to be superior to those of others that identified alcohol abuse or dependence in the elderly, with a sensitivity of $94.9 \%$, specificity of $77.8 \%$, predictive value of $89.4 \%$ and a negative predictive value of $88.6 \%{ }^{(14)}$. Since it was developed especially for the elderly ${ }^{(16)}$, the MAST$\mathrm{G}$ features an easy and simple (dichotomous) response as a characteristic, but is considered by many as relatively long by presenting 24 questions, which can make its administration difficult. However, this instrument has the advantage of addressing perceptions about health and risk behaviors of the elderly, as well as the damage caused by alcohol consumption, which becomes relevant when conducting its validation for the Brazilian context. Specifically for the nursing discipline, this study is of great interest, since professionals integrate health teams in different contexts of action, so that they have favorable conditions to identify problems related to alcohol abuse and dependence among the elderly.

This study had as its objective to evaluate the internal consistency of the version of the MAST-G for the elderly population, translated and adapted for Brazil.

\section{METHOD}

A descriptive, cross-sectional study design was used.

\section{Local and sample}

The study was conducted with elderly residents in the five neighborhoods covered by a Family Health Unit (FHU) in São Carlos, São Paulo, Brazil. In the year 2011, there were $3,958(100 \%)$ families who were enrolled in this FHU, which had among their members 1,540 (38.4\%) elderly people. One hundred twenty eight (8.3\%) of the elderly registered in the Community Health Workers at FHU were invited to participate in the study, according to the inclusion and exclusion criteria. For sample calculation the following parameters were used: prevalence estimation of $8 \%{ }^{(6)}$ for alcohol use in the past year, a confidence interval of $95 \%$, sampling error of $5 \%$. The estimated number was 106 elderly.

The inclusion criteria used were: (1) age greater than or equal to 60 years; (2) resident in the municipality of São Carlos; (3) cut-off on the Mini-Mental State Exam (MMSE) ${ }^{(17)}$ below the classification indicative of possible dementia; (4) presenting a level of independence, measured by the Katz Index ${ }^{(18)}$ with a cut-off score $\geq 5$.

\section{Instruments}

Sociodemographic information contained questions related to sex, age, marital status, level of education, occupation and dwelling.

The Mini-Mental State Exam (MMSE) ${ }^{(17)}$ is one of the instruments used worldwide, employed alone or combined with a broader battery of tests ${ }^{(19)}$. It enables the assessment of cognitive function and screening for dementia. The Brazilian translation ${ }^{(20)}$ and the updated version ${ }^{(21)}$ of the MMSE were used. The instrument has a maximum score of 30 points. For detection of possible dementia, the scores obtained were evaluated according to the level of education, with the following cutoff scores: $<24$ for educated subjects, $<18$ for literate, and <14 for illiterate.

The Index of Independence in Activities of Daily Living (Katz Index) consists of six items with dichotomous responses, related to self-care activities, such as: eating, bathing, dressing, personal hygiene, continence (control of elimination) and mobility. It is the instrument used most frequently in gerontological studies, and enables the evaluation of individual functionality ${ }^{(18)}$. The cut-off point $\geq 5$ was adopted, indicating independence.

The Michigan Alcoholism Screening Test - Geriatric Version (MAST-G) consists of 24 questions with dichotomous responses (yes or no). In this instrument, each yes response has a one point value and the cut-off of five points is used to indicate probable alcohol abuse. A score between zero and four points signifies that there is no evidence of alcoholism, and when there is a total equal to or greater than five points, problems related to the use of alcohol are indicated.

During the administration of the instrument, to formulate the question, if the response is evasive or ambiguous, it is recommended to continue questioning clearly and ask the elderly to choose an answer that is closest to his experience, given his pattern of consumption. A typical difficulty in the application of the MAST-G may occur when the respondent does not consume alcohol. For example, if the respondent consumed abusively and, for some reason, stopped consuming for a month, this complicates the characterization of the pattern of consumption. Therefore, one should consider the amount of drinking and the related symptoms during the period of greatest consumption in the previous year. However, one should make note of the special circumstances in which the respondent is found and the period in which he was assessed ${ }^{(22)}$.

The interview was structured in accordance with the Diagnostic Criteria for Research (DCR-10) of the ICD$10^{(23)}$. This interview enables one to verify if the subject presents a diagnosis of disorders related to alcohol use, subdivided into harmful use or alcohol withdrawal syndrome. It consists of ten questions, with dichotomous responses (yes or no). 


\section{Procedures}

A list containing the names and addresses of the elderly enrolled in the FHU was obtained. Armed with this list, a team composed of five properly trained researchers went to the homes of the elderly. The 128 subjects who met the inclusion criteria were invited to participate in the study; 19 refused to participate, citing fears and/or concerns regarding the use that would be made of the collected information.

Interviews were conducted in the homes of the elderly, after they signed the Terms of Free and Informed Consent (TFIC). The administration of the instruments lasted, on average, 45 minutes and occurred in one encounter. The interviews were conducted in the period of May to August of 2011. After the completion of the MMSE and the Katz Index, the Sociodemographic Information Questionnaire, the ICD-10 criteria, and the MAST-G were administered. None of the subjects were excluded for presenting scores indicative of cognitive or functional compromise. During the administration of the MAST-G, the researcher read each of the 24 questions, asking the interviewee to respond yes or no to the question posed, immediately noting the response on the form.

The translation and transcultural adaptation of the instrument consisted of four steps: translation, back translation, pilot study and judgment of the final instrument ${ }^{(24-25)}$.

First step: Translation. Two translations of the original English instrument to the Portuguese were performed ${ }^{(9)}$, by independent translators whose maternal language was Portuguese and who had good command of English, and were qualified (certified) and oriented to the objectives of the study.

Second step: Back Translation. This version was presented to a native English speaking professional with good command of the Portuguese language, without previous knowledge about the MAST-G, who was asked to perform a back translation of the instrument into English.

Third step: Pilot Study. The two translated versions were presented to ten people with different levels of education, for comment about the interpretation of each of the 24 translated questions. Thereafter, each person was asked to provide a written description about the ease of understanding the questions contained in each of the two versions, and were allowed to provide suggestions for changes to improve the instrument. After this step, a new Portuguese version of the instrument was prepared, by incorporating the suggestions proposed for adequately adjusting and improving the understanding of the questions.

Fourth step: Judgment. Each step consisted of technical review and evaluation of semantical and conceptual equivalence by specialists. A committee of judges was formed of seven people, of whom five members were fluent in the English language and had command of the theme. This committee analyzed the back translation, comparing it to the original version of the instrument, for the identification of problems and discordance, resulting in a list of suggestions and changes for the development of a synthesis version. This final version of the instrument was produced, observing semantic equivalence, idiomatic equivalence (colloquial and idiomatic expressions), cultural or experimental equivalence, conceptual equivalence, and the equivalence score, finalizing the process of adaptation of the Portuguese version of the instrument, which was used in this present study.

This study was authorized by the General Director of Ambulatory Care of the city of São Carlos, SP, Brazil, and approved by the Committee on Ethics in Research involving Human Beings of the Universidade Federal de São Carlos (Federal University of São Carlos - UFSCar) (process no 101/2011).

Statistical analysis. A database was developed and stored in Microsoft Excel 2000. Later, the data were transferred to the Statistical Package for the Social Sciences (SPSS), version 19 for Windows, and to SAS $/$ STATA ${ }^{\circledR}$, version 9, for data analysis. The consistency of the instrument investigated was verified by means of the Cronbach's Alpha, which is calculated with the objective of verifying the internal consistency of the items, and which can assume values between 0 and 1 . The closer it is to 1 , the more reliable the instrument of evaluation, with values equal to or greater than 0.7 considered appropriate ${ }^{(24-28)}$.

To verify the sensibility of the MAST-G and to quantitatively describe the design of the instrument translated for Portuguese, the Receiver Operating Characteristic (ROC) curves were used, establishing the clinical diagnosis of harmful use or alcohol dependence of the ICD-10 as the gold standard.

In general, a diagnostic test is evaluated using two measures (in the present study, scores obtained on the MAST-G and diagnostic criteria according to the ICD-10), defining the sensitivity as the value of true false positive (TFP) and specificity as the value of true false negative (TFN). The ROC curve can be represented on a sensitivity (SE) and specificity (S) plane and one may consider the curve nearest to the upper left corner as the one that provides the greatest discriminating power ${ }^{(28)}$.

\section{RESULTS}

There were 128 elderly people approached, of whom 111 (86.7\%) comprised the sample. Regarding sociodemographic information (Table 1), 50 respondents (45\%) were male and 61 (55\%) were female. The mean age of the elderly patients was 70 years (SD \pm 6.9 ), with no difference between the sexes; the age range varied from 60 to 92 years for the females and 60-82 years for the males. Regarding marital status, 68 (61\%) were married, 26 (23\%) were widowed, nine (8.6\%) were single and eight (7.4\%) declared themselves separated or divorced. A mean of
Use of alcohol in the elderly: transcultural validation of the Michigan Alcoholism Screening Test - Geriatric Version (MAST-G) Kano MY, Santos MA, Pillon SC 
education of only three years of study (SD \pm 3 ) was observed, with 18 seniors (16\%) who declared themselves illiterate or with less than one year of schooling. Regarding residence, 102 elderly (92\%) reported living with family, and only nine (8\%) lived alone.

Table 1 - Sociodemographic characteristics of the sample of elderly patients of the FHU - São Carlos SP, Brazil, 2011

\begin{tabular}{lccc}
\hline & & $\mathrm{n}$ & $\%$ \\
\hline \multirow{2}{*}{ Sex } & Masculine & 50 & 45 \\
& Feminine & 61 & 55 \\
\multirow{3}{*}{ Marital status } & Married & 68 & 61 \\
& Widowed & 26 & 23 \\
& Single & 9 & 8.6 \\
& Separated/Divorced & 8 & 7.4 \\
Education & None & 18 & 16 \\
& $1-2$ years & 29 & 26 \\
& 3-4 years & 47 & 42 \\
Type of dwelling & 5-6 years & 4 & 4 \\
With whom you & Own years & 13 & 12 \\
reside & Rent house / apartment & 100 & 90.9 \\
\hline Not $(\mathrm{n}=111)$ apartment & With family & 102 & 9.1 \\
& Alone & 9 & 8 \\
\hline
\end{tabular}

The calculated mean value of the MMSE for the 111 elderly who participated in the research was 23 points $(S D \pm 3.4)$, on a scale from 0 to 30 , with 23 points (SD \pm 3.2 ) for the men and 23 points (SD \pm 3.5 ) for the women, data not shown in table.

Regarding the use of alcoholic beverages, 54 (48\%) had consumed alcohol in the past 12 months, among which positivity (ICD-10) for harmful use was verified in 43 (79\%) elderly, and 11 (21\%) were abstainers.

Regarding gender, 18 (33.3\%) of those who presented positive criteria for harmful use (ICD-10) were men and 25 (46.3\%) were women, data presented in Table 2.

Table 2 - Classification of alcohol consumption, according to gender of the elderly patients of the FHU - São Carlos SP, Brazil, 2011

\begin{tabular}{lccc}
\hline & & $\mathrm{n}$ & $\%$ \\
\hline \multirow{2}{*}{ Harmful use of alcohol } & Masculine & 18 & 33 \\
& Feminine & 25 & 46 \\
\multirow{2}{*}{ Abstainers } & Masculine & 7 & 13 \\
& Feminine & 4 & 8 \\
\hline
\end{tabular}

Note: $(n=54)$

In the evaluation of the reliability of the MAST-G, a Cronbach's alpha value of 0.7873 was obtained. Of the sample of 111 elderly, 25 (22\%) had five or more yes answers on the instrument, indicating the possibility of presenting problems related to alcohol use ${ }^{(9,28)}$. To test this performance, five different ROC curves were constructed (Figure 1), each taking as its cutoff 2, 3, 4, 5 or 6 yes responses from the 111 administered questionnaires. Table 3 shows the values of the areas under the curves (AUC), calculated for each of the five ROC curves. The curve constructed using only two yes answers as a cutoff value almost overshadowed the diagonal, with an area under the curve of only 0.5486 , indicating complete randomness of responses. Moreover, it was possible to observe a departure from diagonal of the ROC curve and an increase in the area under the curve, when higher cutoff values were used, and the ROC curves with a cutoff of 5 or 6 practically overlapped, with areas of 0.8851 and 0.9051 , respectively. One can understand that positive responses to the 24 items showed great sensitivity to the use of alcoholic beverages, or that there was a high probability that, if a respondent answered yes to five or more questions in the questionnaire, there were problems related to the use or abuse of alcohol.

Table 3 - Area under the curve (AUC) calculated by the five ROC curves - São Carlos, SP, Brazil, 2011

\begin{tabular}{lc}
\hline Curve & AUC \\
\hline 6 YES & 0.9051 \\
5 YES & 0.8851 \\
4 YES & 0.7913 \\
3 YES & 0.7169 \\
2 YES & 0.5486 \\
\hline
\end{tabular}

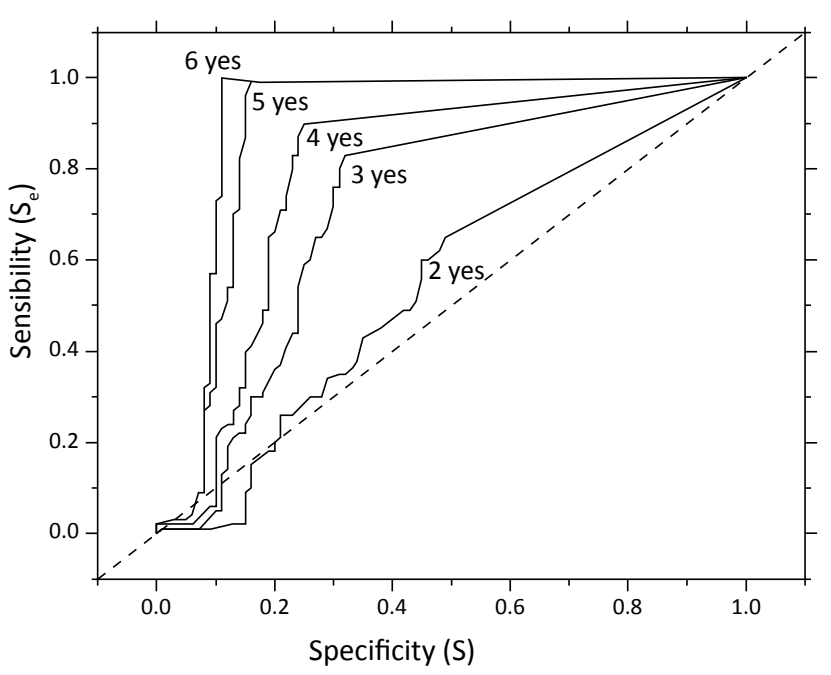

Figure 1 - ROC Curves of the MAST-G in relation to the use of alcohol (ICD-10) by elderly patients of the FHU - São Carlos, SP, Brazil, 2011. $(\mathrm{n}=111)$

\section{DISCUSSION}

Evidence points to the growth in the number of elderly with problems related to the use of alcohol that, although they can be prevented, become inevitable in this age group ${ }^{(10-12)}$. Alcohol abuse places the elderly at higher risk of vulnerability for the development of physical, psychological and social problems, which are not always detected by professionals in different health settings. Thus, estimates of current alcohol consumption in the elderly population vary, but its consequences in this stage of life, in addition to the severity of health problems, have generated a great impact on health care. 
In relation to the sociodemographic characteristics of the elderly, respondents were predominantly female, married, with a low level of education and living with family, with no statistically significant difference when compared by the gender variable. A similar distribution to that obtained in the present study was also observed in other studies that investigated the use of alcohol in the elderly population $^{(4,9,19)}$.

An interesting finding of this study refers to the number of women in the sample, regardless of numerical issue, since there was no difference when compared to men. It is noteworthy that almost half $(46 \%)$ of them presented a harmful pattern of alcoholic beverage consumption. We must mention that $32 \%$ of elderly Brazilians consume alcoholic beverages. However, older men drink in less quantity and frequency when compared to the young, since the problems diminish with age, but strongly differ when comparing the consumption patterns of women from the same age range ${ }^{(6)}$.

On the other hand, several studies about alcohol use, harmful use and dependence in the elderly were developed in samples composed primarily of men, also considering racial issues and individuals with low educational levels, making it difficult to compare data. Furthermore, there is evidence that people who began drinking later did not always present problems at work or face financial problems, nor did they ever have problems with the law due to driving while intoxicated. Nevertheless, even with these difficulties to identify problems related to alcohol use in the elderly, there are studies that show that the prevalence of its abuse by individuals aged 65 or more is far more prevalent among men than women ${ }^{(10-15)}$.

The data obtained are worrying, as the sample was composed of elderly who were recruited at home and who were monitored by professionals of the Family Health Program, in addition to presenting good levels of lucidity and physical independence, as assessed by the MMSE (mean $=23$ points). The fact that they are preserved from the cognitive point of view, and their capacity for autonomy, may facilitate alcohol consumption unperceived by the family and the healthcare team, characterizing this as evidence of an invisible epidemic, since the problems and therefore the rates are underestimated and poorly identified ${ }^{(27,29-30)}$.

In this sense, more studies, training and awareness on the part of health care professionals is fundamental for improving the identification and implementation of effective interventions together with this clientele. It is recommended, therefore, that there be a more effective articulation between health services (primary care), essential for the promotion of continuity of care, especially the geriatric programs and specialized services of treatment for the use of psychoactive substances.

The results encountered for the Brazilian version of the MAST-G indicated that this instrument is very robust and reliable for the detection of problems associated with alcohol abuse or dependence for elderly people. According to the literature ${ }^{(9)}$, a person who responded yes to five or more questions on the MAST-G may have some type of problem with the use of alcohol ${ }^{(9,29)}$. It was observed that there was practically no difference in relationship to the risk of the existence of alcohol problems among the elderly who answered yes to five or more questions, which is consistent with the results obtained for the original MAST-G in the English language ${ }^{(9,30)}$. The translation of the instrument into Portuguese did not change the specificity or sensibility observed in the MAST-G in English, which is expected in the validation work.

One of the greatest challenges that this study faced was the risk that the sensitivity and specificity would be lost or corrupted when translating the 24 questions of the original instrument into Portuguese, requiring much more than five positive responses to adequately identify the existence of risk of abuse or probable alcohol dependence.

The results are quite promising, especially considering that the majority of previous studies with the MAST-G were performed with very specific samples, such as war veterans $^{(29)}$ or elderly who suffered a cerebral vascular $\operatorname{attack}^{(20)}$. However, the absence of results obtained for a second screening instrument, such as the CAGE or AUDIT, may be a limitation of this study for a more precise evaluation of the MAST-G and its comparison with other already validated instruments.

This study showed that the version of the MAST-G translated into Portuguese can be used to identify problems related to alcohol abuse or dependence in the elderly of both sexes. However, it is necessary to consider the possible existence of some bias in the results, caused by the type of sample studied. In the first place, the strategy of seeking elderly for the research from the database of the FHU in São Carlos, SP, Brazil, may have directed the result to a specific type of elderly person who makes use of public health services. This population segment may be different from that using the private services, so the results cannot be generalized. Additionally, the research, while covering both sexes, was limited to elderly people with lower educational levels (mean of three years of study), factors that were specified.

Contrary to the idea generally accepted as common sense, the prevalence of higher levels of alcohol use also occurs in the upper economic strata of society ${ }^{(10)}$. For this reason, it would be important to extend this research to elderly within other socioeconomic strata.

\section{CONCLUSION}

This study sought to evaluate and validate the Portuguese translation of the MAST-G instrument for the detection of problems related to the use or abuse of alcohol or probable alcohol dependence in elderly of both sexes who were patients of the FHU of a Brazilian city. Based on these
Use of alcohol in the elderly: transcultural validation of the Michigan Alcoholism Screening Test - Geriatric Version (MAST-G) Kano MY, Santos MA, Pillon SC 
results, it is considered that the instrument was translated and adapted to Portuguese. The MAST-G was found to be easily understood and the value of the internal consistency index obtained was considered satisfactory.

In relationship to the specificity and sensibility, the same cutoff value of five yes responses was observed, indicative of the existence of problems related to the use/abuse of alcohol by the elderly, corroborating the results presented in studies with the original instrument in English.

It was observed that, despite several authors questioning the time required for the administration of the 24-item questionnaire, the version translated into Portuguese showed that it was an unintimidating instrument and was easy to administer.

Analyses of equivalence of measurement and reproducibility are necessary, as well as an analysis of construct validity, for example, through factor analysis. Another limitation of this study involved the management of the relationship

\section{REFERENCES}

1. World Health Organization. Envelhecimento ativo: uma política de saúde. Trad. Suzana Gontijo. Brasília: Organização Pan-Americana da Saúde; 2005.

2. Veras R. Em busca de uma assistência adequada à saúde do idoso: revisão da literatura e aplicação de um instrumento de detecção precoce e de previsibilidade de agravos. Cad Saúde Pública. 2003;19(3):705-15.

3. Herman S, Sadovsky R. Psychosocial health screening and recognizing early signs of psychosocial distress. J Mens Health. 2010;7(1):73-82

4. Senger AEV, Ely LS, Gandolfi T, Schneider RH, Gomes I, De Carli GA. Alcoolismo e tabagismo em idosos: relação com ingestão alimentar e aspectos socioeconômicos. Rev Bras Geriatr Gerontol. 2011;14(4):713-719.

5. Meloni JR, Laranjeira RR. Custo social e de saúde do consumo de álcool. Rev Bras Psiq. 2004;26 Supl. 1:7-10.

6. Laranjeira R, Pinsky I, Zaleski M, Caetano R. I Levantamento Nacional Sobre os Padrões de Consumo de Álcool na População Brasileira. Brasília: Secretaria Nacional Antidrogas; 2007.

7. Oliveira JB, Santos JLF, Kerr-Corrêa F, Lima MCP. Alcohol screening instruments in elderly male: a population-based survey in metropolitan São Paulo, Brazil. Rev Bras Psiq. 2011;33(1):1-6.

8. Bogstrand ST, Rossow I, Normann PT, Ekeberg $\varnothing$. Studying psychoactive substance use in injured patients: does exclusion of late arriving patients bias the results? Drug Alcohol Depend. 2013;127(1-3):187-92. that exists between the professional and the patient so that they may realize the need to use the instrument, since its use requires a greater expenditure of time and attention for the elderly. Many times the elderly can present with a confused state of mind, debilitation and disorientation. Moreover, the professional usually does not have a suitable work space (such as in a private room in the service) to welcome and receive the elderly and, thus, to guarantee the confidentiality and reliability of the responses.

It was concluded that the MAST-G permitted the investigation of several questions about the drinking behavior of the elderly, favoring a specialized customer service and quality of care. Although the results obtained were in agreement with those found in studies conducted with the original version in English, an important and necessary action would be a combined assessment of the instrument with other tools, in order to compare the results obtained in this validation with other instruments already validated for the Portuguese language.

9. Pillon SC, Cardoso L, Pereira GAM, Mello E. Perfil dos idosos atendidos em um Centro de Atenção Psicossocial - álcool e outras drogas. Esc Anna Nery Rev Enferm. 2010;14(4):742-8.

10. Selzer ML. The Michigan Alcoholism Screening Test: the quest for a new diagnostic instrument. Am J Psychiatr. 1971;127(12):1653-8.

11. Blow FC, Brower KJ, Schulenberg JE, Demo-Dananberg LM, Young JP, Beresford TP. The Michigan Alcoholism Screening Test - Geriatric Version (MAST-G): a new elderly-specific screening instrument. Alcohol Clin Exp Res. 1992;16:372.

12. Dar K. Alcohol use disorders in elderly people? Adv Psychiatr Treat. 2006;12:173-81.

13. Fink A, Tsai MC, Hays RD, Moore AA, Morton SC, Spritzer $\mathrm{K}$, et al. Comparing the alcohol-related problems survey (ARPS) to traditional alcohol screening measures in elderly outpatients. Arch Gerontol Geriatr. 2002;34(1):55-78.

14. Barry KL, Blow FC. Screening, assessing and intervening for alcohol and medication misuse in older adults. In: Lichtenberg PA, editor. Handbook of assessment in clinical gerontology. New York: Academic Press; 2010. p. 307-30.

15. O'Connell $H$, Chin A, Hamilton F, Cunningham C, Walsh J, Coakley $D$, et al. A systematic review of the utility of selfreport alcohol screening instruments in the elderly. Int J Geriatr Psychiatry. 2004;19(11):1074-86.

16. Conigliaro J, Kraemer K, McNeil M. Screening and identification of older adults with alcohol problems in primary care. J Geriatr Psychiatry Neurol. 2000;13(3):106-14. 
17. Folstein MF, Folstein SE, McHugh PR. Mini-Mental State: a practical method for grading the cognitive state of patients for the clinician. J Psychiatr Res. 1975;12(3):189-98.

18. Duarte $\mathrm{YAO}$, Andrade $\mathrm{CL}$, Lebrão $\mathrm{ML}$. O Índex de Katz na avaliação da funcionalidade dos idosos. Rev Esc Enferm USP. 2007;47(2):317-25.

19. Diniz BSO, Volpe FM, Tavares AR. Nível educacional e idade no desempenho no Miniexame do Estado Mental em idosos residentes na comunidade. Rev Psiquiatr Clín. 2007;34(1):13-7.

20. Bertolucci PH, Brucki SM, Campacci SR, Juliano Y. O MiniExame do Estado Mental em uma população geral: impacto da escolaridade. Arq Neuro-Psiquiatr. 1994;52(1):1-7.

21. Lourenço RA, Veras RP. Mini-Exame do Estado Mental: características psicométricas em idosos ambulatoriais. Rev Saúde Pública. 2006;40(4):712-9.

22. Barry KL, Oslin DW, Blow FC. Alcohol problems in older adults: prevention and management. New York: Spring; 2001.

23. Organização Mundial da Saúde. Classificação de transtornos mentais e de comportamento da CID-10: critérios diagnósticos para pesquisa. Porto Alegre: Artes Médicas; 1998.

24. Gonçalves AMS, Pillon SC. Adaptação transcultural e avaliação da consistência interna da versão em português da Spirituality Self Rating Scale (SSRS). Rev Psiquiatr Clin. 2009;36(1):10-5.
25. Callegaro BJ, Damásio BF, Bandeira DR. Adaptação e validação de instrumentos psicológicos entre culturas: algumas considerações. Paidéia. 2012;22(53):423-32.

26. Maroco J, Garcia-Marques T. Qual a confiabilidade do alfa de Cronbach? Questões antigas e soluções modernas? Lab Psicol. 2006;4(1):65-90.

27. Gache $P$, Michaud P, Landrym U, Accietto C, Arfaoui S, Wenger $O$, et al. The Alcohol Use Disorders Identification Test (AUDIT) as a screening tool for excessive drinking in primary care: reliability and validity of a French version. Alcohol Clin Exp Res. 2005;29(11):2001-7.

28. Martinez EZ, Louzada-Neto F, Pereira BB. A curva ROC para testes diagnósticos. Cad Saúde Coletiva. 2003;11(1):7-31.

29. Freedy JR, Ryan K. Alcohol use screening and case finding: screening tools, clinical clues, and making the diagnosis. Prim Care. 2011;38(1):91-103.

30. Jonhson-Greene D, McCaul ME, Roger P. Screening for hazardous drinking using the Michigan Alcohol Screening Test - Geriatric Version (MAST-G) in elderly persons with acute cerebrovascular accidents. Alcohol Clin Exp Res. 2009;33(9):1555-61.
Correspondence addressed to: Sandra Cristina Pillon

Departamento de Enfermagem Psiquiátrica e Ciências Humanas, Escola de Enfermagem de Ribeirão Preto, Universidade de São Paulo Av. Bandeirantes, 3900 - Monte Alegre

CEP 14040-902 - Ribeirão Preto, SP, Brazil

E-mail: pillon@eerp.usp.b 